\title{
HIV-1 protease inhibitor drug resistance in Kenyan antiretroviral treatment-naive and -experienced injection drug users and non-drug users
}

Valentine Budambula ${ }^{1}$, Francis O. Musumba ${ }^{2,3}$, Mark K. Webale², Titus M. Kahiga ${ }^{4}$, Francisca Ongecha-Owuor ${ }^{5}$, James N. Kiarie ${ }^{6}$, George A. Sowayi ${ }^{7}$, Aabid A. Ahmed ${ }^{8}$, Collins Ouma ${ }^{2,9}$ and Tom Were ${ }^{10^{*}}$

\begin{abstract}
Background: Although injection drug use drives antiretroviral drug resistance, the prevalence of protease inhibitor (PI) resistance among Kenyan IDUs remains undetermined. We, therefore, explored PI resistance mutations and their association with viral load and CD4+ T cell counts in HIV-1 infected IDUs (ART-naive, $n=32$; and -experienced, $\mathrm{n}=47$ ) and non-drug users (ART-naive, $\mathrm{n}=21$; and -experienced, $\mathrm{n}=32$ ) naive for PI treatment from coastal Kenya.

Results: Only IDUs harboured major PI resistance mutations consisting of L90M, M46I and D30 N among 3 (6.4\%) ART-experienced and 1 (3.1\%) -naive individuals. Minor PI mutations including A71T, G48E, G48R, I13V, K20I, K20R, L10I, L10V, L33F, L63P, T74S, V1 11, and V32L were detected among the ART-experienced (36.2 Vs. 46.9 \%) and -naive (43.8 vs. $66.7 \%$ ) IDUs and non-drug users, respectively. All the four IDUs possessing major mutations had high viral load while three presented with CD4+ T cell counts of $<500$ cells/ml. Among the ART-naive non-drug users, CD4+ T cell counts were significantly lower in carriers of minor mutations compared to non-carriers $(P<0.05)$.
\end{abstract}

Conclusion: Transmitted drug resistance may occur in IDUs underscoring the need for genotyping resistance before initiating PI treatment.

Keywords: HIV-1, Protease inhibitor, Drug resistance, Antiretroviral, Treatment-naive, Treatment-experienced, Injection drug users, Non-drug users, Coastal Kenya

\section{Background}

Despite up-scaling of antiretroviral drugs for treatment and prevention, HIV-1 remains an important cause of infectious disease burden in the world. In the year 2013, an estimated 35 million people globally were infected with HIV of whom 24.7 million reside in Sub-Saharan Africa [1]. Substance consumption including injection drug use is an emerging epidemic that is driving the high HIV burden on the continent [2]. Among the 243 million people using substances in the world, 12.7 million are injection drug users (IDUs) of whom $13.1 \%$ are living

\footnotetext{
*Correspondence: mugogwe@yahoo.com

${ }^{10}$ Department of Medical Laboratory Sciences, Masinde Muliro University of Science and Technology, P. O. Box 190, Kakamega 50100, Kenya Full list of author information is available at the end of the article
}

with HIV [1]. Africa is home to nearly 1.02 million IDUs of which $12.1 \%$ are harbouring HIV infections [1]. In Kenya, about $18.3 \%$ of the 49,000 IDUs, mainly concentrated in Nairobi and Coastal regions, are living with HIV [3]. Non-drug users are individuals not consuming illicit drugs classified by the United Nations Office on Drug and Crime (UNODC) [1]. However, non-drug users are also at increased risk of acquiring HIV infection, largely through engaging in unprotected and high risk sexual activities with IDUs [4-6]. As such, effective interventions are urgently required to reduce the high burden of HIV in these most-at-risk-populations.

The current standard regimen for first-line HIV treatment in Kenya consists of two nucleoside reverse transcriptase inhibitors (NRTI) mainly tenofovir disoproxil 
fumarate (TDF) or azidovudine (AZT), lamuvudine (3TC) and one non-nucleoside reverse transcriptase inhibitor (NNRTI) efevirenz (EFV) or nevirapine (NVP) [7]. Protease inhibitor (PI) drugs serve as HIV-1 preand post-exposure prophylaxis and substitute treatment in cases of first line antiretroviral treatment failures and/or intolerance [8]. Protease inhibitors are recommended in cases of virological failure, defined as a viral load $>1000$ copies/ml after 12 months of therapy or an increase in the viral load after initial viral suppression [7]. Consequently, PIs have been effective in further lowering HIV-associated morbidity and mortality [9, 10]. However, continued use of PIs as effective salvage treatment is hindered by emergence of drug resistance, largely due to poor accessibility and adherence to treatment [11]. Two classes of point mutations in the protease gene, designated major and minor mutations, mediate resistance to PIs [12]. Major mutations decrease susceptibility to PI drugs leading to poor virologic response and treatment failure, while minor mutations only enhance viral replication in the presence of major mutations [12]. In addition, previous studies reporting higher rates of major and minor PI resistance (24 vs. $8 \%$ ) among ART-experienced PI-naive IDUs compared to non-drug users [10], suggest spontaneous emergence of PI resistance in PI-naive individuals. To our knowledge, no study has concurrently determined rates of PI resistance in ART-naive and -experienced IDUs and non-drug users among PI treatment-naive individuals.

Several studies across Kenya show widespread resistance to NRTIs and non-NNRTIs in ART-naive and -experienced adults and children, breastfeeding infants and IDUs [13-31]. More importantly, previous studies showing $13.8 \%$ resistance rates to first line (NRTIs and NNRTIs) ART regimens among IDUs from Mombasa, coastal Kenya, suggest existence of resistance to these drugs that are commonly used in combination with PIs [27]. In such cases of suspected drug resistance, the NNRTIs (NVP or EFV) or NRTIs (ABC) are often substituted with PIs (either LPV/r or ATV/r) as second-line treatment [7]. In addition, resistance to integrase inhibitors has also been detected in the country [32]. While a number of studies in the country show existence of resistance to PIs in ARTnaive and -experienced individuals in adults and children from the general population, and treatment-naive female sex workers $[16,18,29,33,34]$ no studies to date have established PI resistance in Kenyan IDUs. Since, high drug injection intensity particularly under the selection pressure of antiretroviral therapy accelerates emergence of resistance [35], this cross-sectional study, examined PI resistance in ART-naive and -experienced IDUs from Mombasa, a coastal city in Kenya.

\section{Methods}

\section{Study design and population}

This cross-sectional study was conducted in HIV-1 infected IDUs and non-drug using controls at Bomu Hospital, a social enterprise facility in Mombasa City, coastal Kenya. Injection drug users were recruited via respondent-driven, snowball and makeshift-outreach sampling methods. In the context of the current study, IDUs comprised of individuals exhibiting injection needle-stick scars and reporting a history of injecting any illicit drug classified by UNODC at least once in the previous month [1] while non-drug users were individuals reporting having never used any of the substances and drugs in the UNODC registry [1]. HIV-1 infection status of consenting IDUs and non-drug users was confirmed using Determine ${ }^{\mathrm{TM}}$ (Abbott Laboratories, Tokyo, Japan) and Unigold ${ }^{\mathrm{TM}}$ (Trinity Biotech Plc, Bray, Ireland) in accordance with the Kenya's guidelines for adult HIV testing [36]. Those yielding positive results on both tests were subsequently recruited into the study. In addition, ART-naive study participants had not been initiated on ART. The ART-experienced study participants were on first-line ART (NRTIs and NNRTIs) consisting of TDF or AZT + 3TC + NVP or EFV [37]. None of the participants were on PIs.

\section{Clinical evaluations}

In brief, about, $3.0 \mathrm{ml}$ venous blood was collected from study participants in ethylenediaminetetraacetic acid vacutainer tubes (Becton-Dickinson, Franklin Lakes, USA) and used for enumerating CD4 $+\mathrm{T}$ cells, and plasma harvesting for HIV-1 viral load quantification. A drop of whole blood was applied on Whatman-FTA ${ }^{\circledR}$ 903 cards (Schleicher \& Schuell BioScience, Dassel, Germany) for preparing dry blood spots (DBS) that were stored at $-20{ }^{\circ} \mathrm{C}$ until used for pro-viral DNA extraction. For enumerating CD4+ T cell counts, $5.0 \mu \mathrm{l}$ of blood were stained with $\mathrm{CD} 3 / \mathrm{CD} 4 / \mathrm{CD} 45$ monoclonal antibody reagent (BD Tritest) and analysed on BD FACSCalibur ${ }^{\mathrm{TM}}$ according to the manufacturer's protocols. HIV-1 viral load was determined in $0.2 \mathrm{ml}$ plasma samples using the Abbott Molecular m2000sp sample preparation and m2000rt real-time amplification and detection systems (Abbott Molecular Inc., Illinois, USA) according to the manufacturer's methods.

\section{HIV-1 DNA extraction and amplification}

HIV-1 pro-viral DNA was extracted from DBS using QIAamp $^{\text {TM }}$ DNA blood mini kit (QIAGEN, Valencia, USA) according to the manufacturer's recommendations. HIV-1 pro-viral DNA encoding protease gene was amplified by nested PCR with primers; Nyupol_7 (5'-GGGAATTTTCTTCAGAGCAG-3') 
HXB2 nucleotide position 2125-2144, and Nyupol_8 (5'-TCTTCTGTCAATGGCCATTGT-3') HXB2 nucleotide position 2635-2615 in the first round. Nyupol_9 (5'-TCCTTAACTTCCCTCAAATCACT-3') HXB2 nucleotide position 2241-2264 and Nyupol_10 (5'-CTGGCACGGTTTCAATAG GACT-3') HXB2 nucleotide position 2577-2556 were used in the second round. First and second round PCR was conducted in a $25 \mu \mathrm{l}$ volume containing $5 \mu \mathrm{L}$ DNA, $1 \times$ PCR buffer, $1.5 \mathrm{mM} \mathrm{MgCl}_{2}, 1 \mathrm{U} / \mu \mathrm{L}$ Taq polymerase (KemTaq $^{\circledR}$ ), $200 \mu \mathrm{M}$ of each dNTP (Invitrogen ${ }^{\mathrm{TM}}$, Carlsbad, USA), and $0.5 \mu \mathrm{M}$ of each first or second round primers. Amplification consisted of initial denaturation at $94{ }^{\circ} \mathrm{C}$ for $4 \mathrm{~min}$, followed by 40 cycles of $94{ }^{\circ} \mathrm{C}$ for $15 \mathrm{~s}, 50^{\circ} \mathrm{C}$ for $30 \mathrm{~s}$, and $72{ }^{\circ} \mathrm{C}$ for $1 \mathrm{~min}$, with a final extension of $72{ }^{\circ} \mathrm{C}$ for $5 \mathrm{~min}$. PCR products were electrophoresed in $1 \%$ ethidium bromide-stained agarose gel, and visualized under ultraviolet light. PCR product sizes of approximately $330 \mathrm{bp}$ were diagnostic for HIV-1 pro-viral DNA.

\section{HIV-1 protease inhibitor drug resistance mutations}

PCR amplicons were purified with QIAquick ${ }^{\mathrm{TM}}$ PCR purification kit (Qiagen, Valencia, USA) according to the manufacturer's protocol. Direct sequencing was performed using BigDye ${ }^{\mathrm{TM}}$ sequencing chemistry (Applied Biosystems $^{\circledR}$, Foster City, USA) on an ABI PRISM ${ }^{\circledR}$ 3100 Genetic Analyzer (Applied Biosystems ${ }^{\circledR}$, Foster City, USA) as per the manufacturer's protocols. Primer pair Nyupol_9 and Nyupol_10 was used for forward and reverse sequencing reactions, respectively. Forward and reverse chromatograms were visually inspected and edited for base mis-calls using MEGA version 6.0 [38]. Pair-wise alignment and contiguous sequences were generated using DNA Baser Sequence Assembler version 4.20.0 (Heracle BioSoft, http://www.DnaBaser.com). Protease inhibitor drug resistance mutations were identified and interpreted using Stanford web-based HIV drug resistance database $[39,40]$ and the International AIDS Society-USA (IAS-USA) drug resistance panel [12].

\section{Data analysis}

Data analysis was conducted using IBM $^{\circledR}$ SPSS 20.0 $\left(\mathrm{IBM}^{\circledR}\right.$ SPSS Statistics for Windows, Version 20.0. Armonk, NY: IBM Corp.). Age and CD4+ T cell counts and viral load were compared across study groups using Kruskal-Wallis test and Dunn's post hoc correction for multiple comparisons. Differences in distribution of gender were compared across the study groups using Chisquare test. Rates of resistance mutations in each study group were summarised as numbers and proportions. Statistical significance was set at $P<0.05$.

\section{Ethical considerations}

This study was conducted following ethical approval obtained from Kenyatta University Ethical Review Committee, approval number PKU019/116 of 2012 in accordance with Helsinki declaration [41]. Written informed consent was obtained from all participants prior to enrolment into the study. Confidentiality was maintained throughout the study.

\section{Results}

\section{Baseline characteristics of the study participants}

Baseline characteristics of the study participants are presented in Table 1. Recruitment was within HIV-infected cohort thus sero-conversion rate is unknown. A total of 132 HIV-1 sero-positive study participants were successfully sequenced for protease inhibitor drug resistance. The study participants consisted of IDUs (ART-naive, $\mathrm{n}=32$ and -experienced, $\mathrm{n}=47$ ) and non-drug users (ART-naive, $\mathrm{n}=21$ and -experienced, $\mathrm{n}=32$ ). Gender distribution was similar among the study groups $(P=0.531)$. Age was significantly different across the groups $(P=0.009)$ with ART-naive IDUs (median, 30.1; IQR, 7.2) having younger individuals relative to ARTnaive non-drug users (median, 36.0; IQR, 13.8; $P<0.05$ ). In addition, 20 (42.5\%), 24 (51.1\%) and 3 (6.4 \%) ARTexperienced IDUs while 3 (9.3\%), 7 (21.9\%) and 22 $(68.8 \%)$ ART-experienced non-drug users were on antiretroviral therapy for $<1,1-3$, and $>3$ years, respectively. The CD4+ T cell counts were similar across the study groups $(P=0.379)$. The HIV-1 viral load was significantly different across the study groups $(P=0.004)$ with ART-naive (median, 3.4; IQR, 2.7; $P<0.05$ ) and -experienced (median, 3.5; IQR, 2.7; $P<0.01$ ) IDUs presenting with lower levels compared to ART-naive non-drug users (median, 4.5; IQR, 2.8).

\section{Protease inhibitor drug resistance}

Major and minor HIV-1 protease drug resistance mutations detected in the study participants are shown in Table 2. Although major PI resistance mutations was not detected in the non-drug users, three major PI resistance mutations including L90M, M46I and D30N were detected in $4(5.1 \%)$ IDUs. Interestingly, mutation L90M co-existed with K20R minor mutation in 1 (2.1\%) ART-experienced IDU, while D30N co-existed with T74S+K20R minor mutations in 1 (3.1 \%) ART-naive IDU. In addition, D30N+M46I co-existed with G48E and K20I minor mutations, respectively, in 2 (4.2\%) ARTexperienced IDUs. Fourteen (29.8\%) ART-experienced IDUs harboured only minor mutations comprising of 1(2.1 \%) K20I, 7 (8.5 \%) K20R, 3 (6.4 \%) L10I, 1 (2.1 \%) V32L and 2 (12.5\%) L10V+K20R. In addition, 13 (40.6\%) ART-naive IDUs had only minor mutations including 1 
Table 1 Baseline characteristics of the study participants

\begin{tabular}{|c|c|c|c|c|c|}
\hline \multirow[t]{2}{*}{ Characteristic } & \multicolumn{2}{|l|}{ Non-drug users } & \multicolumn{2}{|c|}{ Injection drug users } & \multirow[t]{2}{*}{$P$} \\
\hline & ART $(-), n=21$ & $\operatorname{ART}(+), n=32$ & ART $(-), n=32$ & $\mathrm{ART}(+), n=47$ & \\
\hline Female, n (\%) & $16(76.2)$ & $20(62.5)$ & $18(56.3)$ & $30(63.8)$ & 0.531 \\
\hline Age, years & $36.0(13.8)$ & $35.2(10.6)$ & $30.1(7.2)^{\mathrm{a}}$ & $31.6(7.4)$ & 0.009 \\
\hline \multicolumn{6}{|l|}{ Duration (years) on ART, n (\%) } \\
\hline$<1$ & $0(0.0)$ & $3(9.3)$ & $0(0.0)$ & $20(42.5)$ & \\
\hline $1-3$ & $0(0.0)$ & $7(21.9)$ & $0(0.0)$ & $24(51.1)$ & - \\
\hline$>3$ & $0(0.0)$ & $22(68.8)$ & $0(0.0)$ & $3(6.4)$ & \\
\hline $\mathrm{CD} 4+\mathrm{T}$ cell counts $/ \mathrm{ml}$ & $568(673)$ & $412(554)$ & $532(472)$ & $426(423)$ & 0.379 \\
\hline $\log _{10}$ HIV-1 RNA, copies/ml & $4.5(2.8)$ & $4.3(1.6)$ & $3.4(2.7)^{\mathrm{a}}$ & $3.5(2.7)^{b}$ & 0.004 \\
\hline
\end{tabular}

Data are presented as medians (IQR, interquartile range) or indicated as number ( $\mathrm{n}$ ) and proportion (\%) of subjects

$A R T(-)$ anti-retroviral treatment-naive, $A R T(+)$ antiretroviral treatment-experienced, HIV-1 human immunodeficiency virus-1

a $P<0.05$ vs. ART (-) non-drug users

b $P<0.01$ vs. ART (-) non-drug users

Significant $P$ values are shown in italic

Table 2 Protease inhibitor drug resistance mutations

\begin{tabular}{|c|c|c|c|c|}
\hline \multirow[t]{2}{*}{ Mutation } & \multicolumn{2}{|l|}{ Non-drug users } & \multicolumn{2}{|c|}{ Injection drug users } \\
\hline & $\operatorname{ART}(-), n=21$ & ART $(+), n=32$ & $\operatorname{ART}(-), n=32$ & $\mathrm{ART}(+), n=47$ \\
\hline $\mathbf{L} 90 \mathbf{M}+\mathrm{K} 20 \mathrm{R}$ & $0(0.0)$ & $0(0.0)$ & $0(0.0)$ & $1(2.1)$ \\
\hline $\mathbf{D} 30 \mathbf{N}+\mathrm{T} 74 \mathrm{~S}+\mathrm{K} 20 \mathrm{R}$ & $0(0.0)$ & $0(0.0)$ & $1(3.1)$ & $0(0.0)$ \\
\hline $\mathbf{D} 30 \mathbf{N}+\mathbf{M} 46 \mathbf{I}+\mathrm{G} 48 \mathrm{E}$ & $0(0.0)$ & $0(0.0)$ & $0(0.0)$ & $1(2.1)$ \\
\hline $\mathbf{D} 30 \mathbf{N}+\mathbf{M} 46 \mathbf{I}+\mathrm{K} 20 \mathrm{I}$ & $0(0.0)$ & $0(0.0)$ & $0(0.0)$ & $1(2.1)$ \\
\hline G48E & $0(0.0)$ & $0(0.0)$ & $1(3.1)$ & $0(0.0)$ \\
\hline G48R & $0(0.0)$ & $0(0.0)$ & $1(3.1)$ & $0(0.0)$ \\
\hline K20l & $1(7.1)$ & $0(0.0)$ & $0(0.0)$ & $1(2.1)$ \\
\hline K20R & $8(38.1)$ & $5(15.6)$ & $5(15.6)$ & $7(8.5)$ \\
\hline L10l & $2(9.5)$ & $0(0.0)$ & $2(6.3)$ & $3(6.4)$ \\
\hline L10V & $0(0.0)$ & $2(6.3)$ & $1(3.1)$ & $0(0.0)$ \\
\hline L33F & $0(0.0)$ & $2(6.3)$ & $0(0.0)$ & $0(0.0)$ \\
\hline V32L & $0(0.0)$ & $0(0.0)$ & $0(0.0)$ & $1(2.1)$ \\
\hline $113 V+L 63 P$ & $0(0.0)$ & $1(3.1)$ & $0(0.0)$ & $0(0.0)$ \\
\hline$L 10 I+K 20 R$ & $1(7.1)$ & $0(0.0)$ & $1(3.1)$ & $0(0.0)$ \\
\hline$L 10 V+K 20 R$ & $0(0.0)$ & $1(3.1)$ & $2(6.3)$ & $2(4.3)$ \\
\hline $\mathrm{L} 10 \mathrm{~V}+\mathrm{T} 74 \mathrm{~S}$ & $0(0.0)$ & $3(9.4)$ & $0(0.0)$ & $0(0.0)$ \\
\hline L10V + V11I & $2(9.5)$ & $0(0.0)$ & $0(0.0)$ & $0(0.0)$ \\
\hline $\mathrm{L} 33 \mathrm{~F}+\mathrm{A} 71 \mathrm{~T}$ & $0(0.0)$ & $1(3.1)$ & $0(0.0)$ & $0(0.0)$ \\
\hline
\end{tabular}

Data presented are number and proportion of subjects. Mutations are denoted based on Stanford drug resistance database and International Antiviral Society-USA drug resistance mutations panel $[12,39,40]$, where number shows amino acid position in the protease gene, and letter before position is wild type amino acid and after the position mutant amino acid

Major mutations are shown in bold

$A$ alanine, $D$ aspartic acid, $E$ glutamic acid, $F$ phenylalanine, $G$ glycine, $I$ isoleucine, $K$ lysine, $L$ leucine, $M$ methionine, $N$ asparagine, $P$ proline, $R$ arginine, $S$ serine, $T$ threonine, $V$ valine, $A R T(-)$ antiretroviral treatment-naive, $A R T(+)$ antiretroviral treatment-experienced, HIV-1 human immunodeficiency virus type- 1

(3.1\%) G48E, 1 (3.1 \%) G48R, 5 (15.6\%) K20R, 2 (6.3\%) L10I, 1 (3.1\%) L10V, 1 (3.1\%) L101+K20R and $2(6.3 \%)$ $\mathrm{L} 10 \mathrm{~V}+\mathrm{K} 20 \mathrm{R}$.

In non-drug users, 15 (46.9\%) ART-experienced individuals had minor mutations consisting of 5
(15.6 \%) K20R, 2 (6.3 \%) L10V, 2 (6.3 \%) L33F, 1 (3.1\%) I13V + L63P, 1 (3.1\%) L10V + K20R, 3 (9.4\%) $\mathrm{L} 10 \mathrm{~V}+\mathrm{T} 74 \mathrm{~S}$ and 1 (3.1\%) L33F + A71T. In addition, 14 (66.7 \%) ART-naive non-drug users harboured minor mutations comprising of 1 (7.1 \%) K20I, 8 (38.1 \%) K20R, 
2 (9.5 \%) L10I, 1 (7.1 \%) L101 + K20R, and 2 (9.5 \%) $\mathrm{L} 10 \mathrm{~V}+\mathrm{V} 11 \mathrm{I}$.

Association of protease inhibitor resistance with viral load and CD4+ $T$ cell counts

Viral load and CD4+ $\mathrm{T}$ cell counts of individuals with major and minor mutations are presented in Tables 3 and 4, respectively. All the four individuals harbouring major mutations presented with high viral load of 4624, 291,124, 141,341 and 209,871 copies/ml, which was greater than 1000 copies $/ \mathrm{ml}$ viral load threshold required for viral suppression in the community [42]. In addition, three of the individuals with major mutations presented with CD4+ T cell counts of 473, 39, and 162 cells/ $\mu 1$ which were $<500$ cells $/ \mu$ l. Carriage of minor mutations was not associated with viral load in all the study groups $(P>0.05)$, but among ART-naive non-drug users, CD4+ $\mathrm{T}$ cell counts were significantly lower in carriers of minor mutations compared to non-carriers (median, 455; IQR , 599 vs. 989,$507 ; P=0.005)$.

\section{Discussion}

Effective use of protease inhibitors in HIV-1 treatment and prevention is largely impeded by the increasing development and spread of acquired and transmitted resistance [43]. Antiretroviral treatment-naive and -experienced IDUs are at an increased risk of acquiring antiretroviral drug resistance as a consequence of high risk sexual and injection practices [44]. In addition, increased selection of protease drug resistance in ART-experienced IDUs is linked to high drug injection intensity and poor adherence to treatment $[35,44]$. Thus, continuous surveillance of drug resistance is important in planning for effective and successful treatment programs in IDUs. This study, determined PI resistance in ART-naive and -experienced IDUs in Mombasa City, in the coastal region in Kenya.

In the current study, major PI mutations were detected only in IDUs with the antiretroviral treatment-experienced (L90M, D30N and M46I) individuals having higher rates than -naive $(\mathrm{D} 30 \mathrm{~N})$ individuals. Most importantly,

Table 3 HIV-1 viral load and CD4+ T cell counts of individuals with major protease inhibitor drug resistance mutations

\begin{tabular}{|c|c|c|c|c|c|c|}
\hline ID & Mutation & Age, years & Gender & $\begin{array}{l}\text { ART duration, } \\
\text { years }\end{array}$ & $\begin{array}{l}\text { HIV-1 RNA ( } \log _{10} \text { HIV-1 RNA), } \\
\text { copies } / \mathrm{ml}\end{array}$ & CD4+ T cells/ml \\
\hline$\# 1$ & $\mathbf{D} 30 \mathbf{N}+\mathbf{M} 46 \mathbf{I}+\mathrm{G} 48 \mathrm{E}$ & 36.4 & $M$ & $<0.5$ & $4624(3.7)$ & 473 \\
\hline \#2 & $\mathbf{L} 90 \mathbf{M}+\mathrm{K} 20 \mathrm{R}$ & 34.6 & $M$ & $1-3$ & $291,124(5.5)$ & 637 \\
\hline \#3 & $\mathbf{D} 30 \mathbf{N}+\mathbf{M} 46 \mathbf{I}+\mathrm{K} 20 \mathrm{I}$ & 30.1 & $\mathrm{~F}$ & $1-3$ & $141,341(5.2)$ & 39 \\
\hline$\# 4$ & $\mathbf{D} 30 \mathbf{N}+\mathrm{T} 74 \mathrm{~S}+\mathrm{K} 20 \mathrm{R}$ & 33.3 & $M$ & Naive & $209,871(5.3)$ & 162 \\
\hline
\end{tabular}

Mutations are denoted according to Stanford drug resistance database and International Antiviral Society-USA drug resistance mutations panel [12, 39, 40] Major mutations are shown in bold

$D$ aspartic acid, $E$ glutamic acid, $G$ glycine, I isoleucine, $K$ lysine, $L$ leucine, $M$ methionine, $N$ asparagine, $S$ serine; $T$ threonine, $A R T$ antiretroviral therapy, $H I V-1$ human immunodeficiency virus type-1

Table 4 Association between minor protease inhibitor resistance mutations, viral load and CD4+ T cell count

\begin{tabular}{|c|c|c|c|c|c|c|}
\hline & \multicolumn{6}{|l|}{ Injection drug users } \\
\hline & \multicolumn{3}{|l|}{ ART (-) } & \multicolumn{3}{|l|}{ ART (+) } \\
\hline & Mutation (-), $n=18$ & Mutation $(+), n=13$ & $P$ & Mutation (-), $n=30$ & Mutation $(+), n=14$ & $P$ \\
\hline CD4+ T cell count $/ \mu l$ & $529(276)$ & $568(597)$ & 0.708 & $412(415)$ & $424(648)$ & 0.762 \\
\hline \multirow[t]{4}{*}{$\underline{\log _{10} \text { HIV-1 RNA, copies/ml }}$} & $4.4(2.7)$ & $2.2(1.9)$ & 0.183 & $3.6(2.7)$ & $2.2(1.7)$ & 0.142 \\
\hline & \multicolumn{6}{|l|}{ Non-drug users } \\
\hline & \multicolumn{3}{|l|}{ ART (-) } & \multicolumn{3}{|l|}{ ART (+) } \\
\hline & Mutation (-), $n=7$ & Mutation $(+), n=14$ & $P$ & Mutation $(-), n=17$ & Mutation $(+), n=15$ & $P$ \\
\hline CD4+T cell count/ $\mu \mathrm{l}$ & $989(507)$ & 455 (599) & 0.005 & $351(526)$ & $554(461)$ & 0.350 \\
\hline $\log _{10}$ HIV-1 RNA, copies/ml & $3.6(1.9)$ & $4.8(2.5)$ & 0.313 & $4.3(1.3)$ & $4.3(2.0)$ & 0.852 \\
\hline
\end{tabular}

Data presented are medians (IQR, interquartile range) in carriers and non-carriers of only minor protease resistance mutations. Statistical analysis was performed using Mann-Whitney test

Significant $P$-values are shown in italic

$A R T(-)$ anti-retroviral treatment-naive, $A R T(+)$ anti-retroviral treatment-experienced, Mutation (+) minor protease resistance mutation carrier, Mutation (-) minor protease resistance mutation non-carrier, HIV-1 human immunodeficiency virus type 
major mutations, D30N and M46I co-existed with minor mutations, G48E, K20I and T74S, suggesting that these mutations mediate evolution of major drug resistance [45]. Our findings of L90M, D30N, and M46I mutations, are partly consistent with previous studies reporting on the presence of major PI mutations D30N and M46I in ART-naive sex workers, a most-at-risk-population from Nairobi, Kenya [34]. Our results are also, in part, consistent with previous studies in Canada showing D30N, M46I, and L90M PI resistance mutations among individuals reporting a history of injection drug use [46]. Likewise, our results are similar to previous studies showing presence of L90M, D30N, and M46I mutations among antiretroviral-naive IDUs in Rio de Janeiro, Brazil [47]. Importantly, phenotypic and/or clinical evidence indicate that D30N mutation confers high-level resistance to nelfinavir; L90M imparts resistance to nelfinavir, sequinavir, indinavir, and lopinavir; while M46I confers resistance to indinavir, lopinavir, fosamprenavir and nelfinavir [12, $39,40]$. In this study, most of the ART-experienced IDUs and non-drug users had been receiving first-line antiretroviral treatment (NRTIs and NNRTIs) for at least a year, eliminating the possibility of cross-resistance to PIs [12]. Although not determined in the current study, it is possible that development of major PI resistance in ART-experienced IDUs is attributable to PI transmitted drug resistance, increased drug-injection frequency, particularly under the selection pressure of antiretroviral therapy [35]. Therefore, tipranavir/ritonavir and darunavir/ritonavir to which the above mutations have no effect [12] may be adopted as drugs of choice for second line treatment in Kenyan IDUs. Altogether, screening prior to initiating highly active antiretroviral therapy (HAART), monitoring of treatment and routine surveillance are important in achieving effective clinical care and preventing emergence and spread of resistance in this most-at-risk-population.

Overall, higher rates of minor mutations were found in IDUs relative to non-drug users, suggesting heterogeneity of HIV-1 strains in IDUs. The detection of A71T, G48E/R, I13V, K20I/R, L10I/V, L33F, L63P, T74S, V11I, and V32L minor mutations in this study is, in part, consistent with previous studies that reported K20R, L10I/V, L33F/I, and L63P minor mutations among HIV-positive women attending antenatal clinics in a large HIV treatment study in western Kenya [33]. In addition, our results corroborate previous studies showing K20I/M/R, L10I/V, I13V, and L63P minor mutations among HIV infected treatment-naive individuals in Morocco [48]. Of note are the higher rates of minor PI mutations in antiretroviral treatment-naive individuals in both the IDUs and non-drug users supporting a mechanism(s) of spontaneous emergence [49]. However, it is also possible that drug-related selective pressure enhances development of minor resistance in IDUs [35].

The high viral load among individuals carrying major PI mutations is consistent with phenotypic and clinical studies showing absence or low virologic response in patients having these major mutations [50]. It is important to emphasize that three of the individuals with major mutations concurrently harboured G48E, K20I, K20R and T74S minor mutations. This is not surprising because G48E inhibits as K20I, K20R and T74S enhance viral replication $[12,51]$. In addition, $\mathrm{CD} 4+\mathrm{T}$ cell counts were $<500$ cells $/ \mu l$ in three of the patients, indicating progression to immunodeficiency. Although minor PI mutations do not directly cause reduced phenotypic and/or clinical response to PI resistance [12], the lower CD4+ T cell counts observed in ART-naive users possibly suggests that minor mutations may contribute to viral fitness and infectivity in treatment-naive individuals [52]. This hypothesis is underscored by previous studies reporting that polymorphic compensatory mutations in the protease gene, may improve the replicative capacity of HIV-1 even in the absence of drug selective pressure or major resistance mutations [52]. Interestingly, previous studies have also reported low CD4 $+\mathrm{T}$ cell counts in anti-retroviral treatment naive IDUs harbouring minor PI mutations [53]. Therefore, our findings suggest that appearance of minor PI mutations may indicate disease progression among newly-infected individuals.

While a prospective design would have been important in examining the emergence of PI resistance in treatment-naive and -experienced IDUs, this cross-sectional study provides the first baseline evidence of occurrence of PI resistance in IDUs from Kenya. Although specific antiretroviral regimens used by the ART-experienced individuals were not evaluated in this study, poor adherence to ART by injection drug users, generate suboptimal antiretroviral drug levels that exert selective pressure on the viral genome leading to resistance [44]. Since interactions of substances consumed and antiretroviral drugs in IDUs cause hepatic hyper-inflammation and derangements in metabolic functions $[54,55]$, toxicological analysis and monitoring of response to ART in a prospective approach will provide insights into the mechanisms underlying development of resistance. In addition, analysis of mutations outside the protease gene, such as env [56] that confer resistance to PI will identify additional mutants mediating resistance.

\section{Conclusion}

Protease inhibitor transmitted drug resistance is likely to occur among Kenyan IDUs. Therefore, performing HIV-1 drug resistance analyses prior to initiating PI treatment in HIV patients from high-risk population groups is critical 
in achieving better treatment outcomes and prolonging the effectiveness of these drugs in the country.

\section{Sequence data}

The 125 sequences described in this study were submitted to the GenBank under accession numbers: KP791995, KP791996, KP791997, KP791998, KP791999, KP792000, KP792001, KP792002, KP792003, KP792004, KP792005, KP792006, KP792007, KP792008, KP792009, KP792010, KP792011, KP792012, KP792013, KP792014, KP792015, KP792016, KP792017, KP792018, KP792019, KP792020, KP792021, KP792022, KP792023, KP792024, KP792025, KP792026, KР792027, KP792028, КР792029, КР792030, KP792031, KP792032, KP792033, KP792034, KP792035, KP792036, KP792037, KP792038, KP792039, KP792040, KP792041, KP792042, KP792043, KP792044, KP792045, KP792046, KP792047, KP792048, KP792049, KP792050, KP792051, KР792052, KР792053, КР792054, КР792055, KP792056, KР792057, KР792058, КР792059, КР792060, KP792061, KP792062, KP792063, KP792064, KP792065, KP792066, KP792067, KP792068, KP792069, KP792070, KP792071, KP792072, KP792073, KP792074, KP792075, KP792076, KP792077, KP792078, KP792079, KP792080, KP792081, KP792082, KP792083, KP792084, KP792085, KP792086, KP792087, KP792088, KP792089, KP792090, KP792091, KP792092, KP792093, KP792094, KP792095, KP792096, KP792097, KP792098, KP792099, KP792100, KP792101, KP792102, KP792103, KP792104, KP792105, KP792106, KP792107, KP792108, KP792109, KP792110, KP792111, KP792112, KP792113, KP792114, KP792115, KP792116, KP792117, KP792118, KP792119, КТ033003, KT033004, КT033005, КТ033006, КТ033007, КT033008, and KT033009.

\section{Authors' contributions}

TW and VB conceived and designed the study. TW, FOM and MWK performed laboratory, statistical and bioinformatics analyses. TW, FOM, MWK co-drafted the manuscript. AA was involved in study design, and clinical analyses. TMK, FOO, JNK, GA, and CO critically revised the manuscript. VB and FOM contributed equally to the writing of this manuscript. All authors read and approved the final manuscript.

\section{Author details \\ ${ }^{1}$ Department of Environment and Health Sciences, Technical University of Mombasa, Mombasa, Kenya. ${ }^{2}$ Department of Biomedical Science and Tech- nology, Maseno University, Maseno, Kenya. ${ }^{3}$ Centre for Virus Research, Kenya Medical Research Institute, Nairobi, Kenya. ${ }^{4}$ Department of Pharmacy and Complementary Medicine, Kenyatta University, Nairobi, Kenya. ${ }^{5}$ Depart- ment of Medicine, Therapeutics, Dermatology and Psychiatry, Kenyatta Uni- versity, Nairobi, Kenya. ${ }^{6}$ Department of Obstetrics and Gynecology, University of Nairobi, Nairobi, Kenya. ${ }^{7}$ Department of Medical Laboratory Sciences, Masinde Muliro University of Science and Technology, Kakamega, Kenya. ${ }^{8}$ Bomu Hospital, Mombasa, Kenya. ${ }^{9}$ Health Challenges and Systems Program, African Population and Health Research Centre, Nairobi, Kenya. ${ }^{10}$ Depart- ment of Medical Laboratory Sciences, Masinde Muliro University of Science and Technology, P. O. Box 190, Kakamega 50100, Kenya.}

\section{Acknowledgements}

We thank the study participants for participating in the study. We are also grateful to staff and management of Bomu Hospital for their support during the study. We thank Raphael Lihana for technical advice on laboratory, bioinformatic analyses and critical review of this manuscript. This research was partly funded by National Commission on Science, Technology and Innovation (NCST/5/003/065) and Partnership for Innovative Medical Education in Kenya (NIH IR24TW008889) awards to TW and VB.

\section{Compliance with ethical guidelines}

\section{Competing interests}

The authors declare that they have no competing interests.

Received: 2 March 2015 Accepted: 7 August 2015

Published online: 15 August 2015

\section{References}

1. UNODC (2014) World drug report 2014

2. Reid SR (2009) Injection drug use, unsafe medical injections, and HIV in Africa: a systematic review. Harm Reduct J 6:24

3. NASCOP, MOH (2012) MARPs surveillance report 2012. NASCOP, Nairobi

4. Hacker MA, Leite I, Friedman SR, Carrijo RG, Bastos FI (2009) Poverty, bridging between injecting drug users and the general population, and "interiorization" may explain the spread of HIV in southern Brazil. Health Place 15:514-519

5. Masur H, Michelis MA, Wormser GP, Lewin S, Gold J, Tapper ML, Giron J, Lerner CW, Armstrong D, Setia U et al (1982) Opportunistic infection in previously healthy women. Initial manifestations of a communityacquired cellular immunodeficiency. Ann Intern Med 97:533-539

6. Panda S, Chatterjee A, Bhattacharya SK, Manna B, Singh PN, Sarkar S, Naik TN, Chakrabarti S, Detels R (2000) Transmission of HIV from injecting drug users to their wives in India. Int J STD AIDS 11:468-473

7. NASCOP, MOH (2014) Guidelines on use use of antiretroviral drugs for treating and preventing HIV infection: a rapid advice. NASCOP, Nairobi

8. WHO (2014) March 2014 supplement to the 2013 consolidated guidelines on the use of antiretroviral drugs for treating and preventing HIV infection. Recommendations for a public health approach

9. Floridia M, Fragola V, Galluzzo CM, Giannini G, Pirillo MF, Andreotti M, Tomino C, Vella S (2002) HIV-related morbidity and mortality in patients starting protease inhibitors in very advanced HIV disease (CD4 count of $<50$ cells/microL): an analysis of 338 clinical events from a randomized clinical trial. HIV Med 3:75-84

10. Kowalski J, Gange SJ, Schneider MF, Tsai HL, Templeton A, Shao Q, Zhang GW, Yeh MF, Young M, Markham RB (2009) Relationship of injection drug use, antiretroviral therapy resistance, and genetic diversity in the HIV-1 pol gene. J Acquir Immune Defic Syndr 50:381-389

11. Ajose O, Mookerjee S, Mills EJ, Boulle A, Ford N (2012) Treatment outcomes of patients on second-line antiretroviral therapy in resourcelimited settings: a systematic review and meta-analysis. AIDS 26:929-938

12. Wensing AM, Calvez V, Gunthard HF, Johnson VA, Paredes R, Pillay D, Shafer RW, Richman DD (2014) 2014 Update of the drug resistance mutations in HIV-1. Top Antivir Med 22:642-650

13. Beck IA, Deng W, Payant R, Hall R, Bumgarner RE, Mullins JI, Frenkel LM (2014) Validation of an oligonucleotide ligation assay for quantification of human immunodeficiency virus type 1 drug-resistant mutants by use of massively parallel sequencing. J Clin Microbiol 52:2320-2327

14. Chung MH, Beck IA, Dross S, Tapia K, Kiarie JN, Richardson BA, Overbaugh J, Sakr SR, John-Stewart GC, Frenkel LM (2014) Oligonucleotide ligation assay detects HIV drug resistance associated with virologic failure among antiretroviral-naive adults in Kenya. J Acquir Immune Defic Syndr 67:246-253

15. Graham SM, Masese L, Gitau R, Jalalian-Lechak Z, Richardson BA, Peshu N, Mandaliya K, Kiarie JN, Jaoko W, Ndinya-Achola J et al (2010) Antiretroviral adherence and development of drug resistance are the strongest predictors of genital HIV-1 shedding among women initiating treatment. J Infect Dis 202:1538-1542

16. Hassan AS, Mwaringa SM, Obonyo CA, Nabwera HM, Sanders EJ, Rinke de Wit TF, Cane PA, Berkley JA (2013) Low prevalence of transmitted HIV type 1 drug resistance among antiretroviral-naive adults in a rural HIV clinic in Kenya. AIDS Res Hum Retroviruses 29:129-135 
17. Hassan AS, Nabwera HM, Mwaringa SM, Obonyo CA, Sanders EJ, Rinke de Wit TF, Cane PA, Berkley JA (2014) HIV-1 virologic failure and acquired drug resistance among first-line antiretroviral experienced adults at a rural HIV clinic in coastal Kenya: a cross-sectional study. AIDS Res Ther $11: 9$

18. Kiptoo M, Brooks J, Lihana RW, Sandstrom P, Ng'ang'a Z, Kinyua J, Lagat N, Okoth F, Songok EM (2013) HIV-1 drug resistance-associated mutations among HIV-1 infected drug-naive antenatal clinic attendees in rural Kenya. BMC Infect Dis 13:517. doi:10.1186/1471-2334-13-517

19. Kiptoo M, Ichimura H, Wembe RL, Ng'Ang'a Z, Mueke J, Kinyua J, Lagat N, Okoth F, Songok EM (2008) Prevalence of nevirapine-associated resistance mutations after single dose prophylactic treatment among antenatal clinic attendees in north rift Kenya. AIDS Res Hum Retroviruses 24:1555-1559

20. Koigi P, Ngayo MO, Khamadi S, Ngugi C, Nyamache AK (2014) HIV type 1 drug resistance patterns among patients failing first and second line antiretroviral therapy in Nairobi, Kenya. BMC Res Notes 7:890

21. Lehman DA, Chung MH, Mabuka JM, John-Stewart GC, Kiarie J, Kinuthia J, Overbaugh J (2009) Lower risk of resistance after short-course HAART compared with zidovudine/single-dose nevirapine used for prevention of HIV-1 mother-to-child transmission. J Acquir Immune Defic Syndr 51:522-529

22. Lehman DA, Wamalwa DC, McCoy CO, Matsen FA, Langat A, Chohan BH, Benki-Nugent S, Custers-Allen R, Bushman FD, John-Stewart GC, Overbaugh J (2012) Low-frequency nevirapine resistance at multiple sites may predict treatment failure in infants on nevirapine-based treatment. J Acquir Immune Defic Syndr 60:225-233

23. Lihana RW, Khamadi SA, Lubano K, Lwembe R, Kiptoo MK, Lagat N, Kinyua JG, Okoth FA, Songok EM, Makokha EP, Ichimura H (2009) HIV type 1 subtype diversity and drug resistance among HIV type 1-infected Kenyan patients initiating antiretroviral therapy. AIDS Res Hum Retroviruses 25:1211-1217

24. Lihana RW, Khamadi SA, Lubano K, Mwangi J, Kinyua JG, Okoth VO, Lagat NJ, Okoth FA, Songok EM, Makokha EP (2010) Genetic characterization of HIV type 1 among patients with suspected immune reconstitution inflammatory syndrome after initiation of antiretroviral therapy in Kenya. AIDS Res Hum Retroviruses 26:833-838

25. Lwembe R, Ochieng W, Panikulam A, Mongoina CO, Palakudy T, Koizumi Y, Kageyama S, Yamamoto N, Shioda T, Musoke R et al (2007) Anti-retroviral drug resistance-associated mutations among non-subtype B HIV-1-infected Kenyan children with treatment failure. J Med Virol 79:865-872

26. Nyamache AK, Waihenya R, Ng'ang'a ZW, Muigai AW, Khamadi SA (2011) Reverse transcriptase inhibitors drug resistance mutations in drug-naive HIV type 1 positive Kenyans. East Afr Med J 88:4-8

27. Osman S, Lihana RW, Kibaya RM, Ishizaki A, Bi X, Okoth FA, Ichimura H, Lwembe RM (2013) Diversity of HIV type 1 and drug resistance mutations among injecting drug users in Kenya. AIDS Res Hum Retroviruses 29:187-190

28. Sigaloff KC, Mandaliya K, Hamers RL, Otieno F, Jao IM, Lyagoba F, Magambo B, Kapaata A, Ndembi N (2012) Rinke de Wit TF: Short communication: High prevalence of transmitted antiretroviral drug resistance among newly HIV type 1 diagnosed adults in Mombasa, Kenya. AIDS Res Hum Retroviruses 28:1033-1037

29. Steegen K, Luchters S, Dauwe K, Reynaerts J, Mandaliya K, Jaoko W, Plum J, Temmerman M, Verhofstede C (2009) Effectiveness of antiretroviral therapy and development of drug resistance in HIV-1 infected patients in Mombasa, Kenya. AIDS Res Ther 6:12

30. Wamalwa DC, Lehman DA, Benki-Nugent S, Gasper MA, Gichohi R, Maleche-Obimbo E, Farquhar C, John-Stewart GC, Overbaugh J (2013) Long-term virologic response and genotypic resistance mutations in HIV-1 infected Kenyan children on combination antiretroviral therapy. J Acquir Immune Defic Syndr 62:267-274

31. Zeh C, Weidle PJ, Nafisa L, Lwamba HM, Okonji J, Anyango E, Bondo P, Masaba R, Fowler MG, Nkengasong JN et al (2011) HIV-1 drug resistance emergence among breastfeeding infants born to HIV-infected mothers during a single-arm trial of triple-antiretroviral prophylaxis for prevention of mother-to-child transmission: a secondary analysis. PLoS Med 8:e1000430

32. Nyamache AK, Muigai AW, Nganga Z, Khamadi SA (2011) HIVType 1 genetic diversity and naturally occurring polymorphisms in HIV type
1 Kenyan isolates: implications for integrase inhibitors. AIDS Res Hum Retroviruses 28:933-936

33. Kantor R, DeLong A, Balamane M, Schreier L, Lloyd RM Jr, Injera W, Kamle L, Mambo F, Muyonga S, Katzenstein D et al (2014) HIV diversity and drug resistance from plasma and non-plasma analytes in a large treatment programme in western Kenya. J Int AIDS Soc 17:19262

34. Sampathkumar R, Shadabi E, La D, Ho J, Liang B, Kimani J, Ball T, Francis A Plummer FA, Luo M (2014) Naturally occurring protease inhibitor resistance mutations and their frequencies in HIV proviral sequences of drugnaïve sex workers in Nairobi, Kenya. In: 16th International Conference on Human Retroviruses:HTLV and Related Viruses. Montreal, Canada. BMC retrovirology

35. Carneiro M, Yu XF, Lyles C, Templeton A, Weisstein AE, Safaeian M, Farzadegan H, Vlahov D, Markham RB (1999) The effect of drug-injection behavior on genetic evolution of HIV-1. J Infect Dis 180:1025-1032

36. NASCOP (2010) National Guidelines for HIV Testing and Counselling in Kenya, 2nd edn. MOPHS, Nairobi

37. NASCOP (2012) Guidelines for antiretroviral therapy in Kenya 2011, 4th edn. Ministry of Medical Services, Kenya, Nairobi

38. Tamura K, Stecher G, Peterson D, Filipski A, Kumar S (2013) MEGA6: molecular evolutionary genetics analysis version 6.0. Mol Biol Evol 30:2725-2729

39. Rhee SY, Taylor J, Fessel WJ, Kaufman D, Towner W, Troia P, Ruane P, Hellinger J, Shirvani V, Zolopa A, Shafer RW (2010) HIV-1 protease mutations and protease inhibitor cross-resistance. Antimicrob Agents Chemother 54:4253-4261

40. Shafer RW, Schapiro JM (2008) HIV-1 drug resistance mutations: an updated framework for the second decade of HAART. AIDS Rev 10:67-84

41. Parsa-Parsi RW, Ellis R, Wiesing U (2014) Fifty years at the forefront of ethical guidance: the world medical association declaration of Helsinki. South Med J 107:405-406

42. Jordan MR, Bennett DE, Bertagnolio S, Gilks CF, Sutherland D (2008) World Health Organization surveys to monitor HIV drug resistance prevention and associated factors in sentinel antiretroviral treatment sites. Antivir Ther 13(Suppl 2):15-23

43. Ssemwanga D, Lihana RW, Ugoji C, Abimiku A, Nkengasong J, Dakum P, Ndembi N (2015) Update on HIV-1 Acquired and Transmitted Drug Resistance in Africa. AIDS Rev 17:3-20

44. Vlahov D, Celentano DD (2006) Access to highly active antiretroviral therapy for injection drug users: adherence, resistance, and death. Cad Saude Publica 22:705-718

45. Wainberg MA, Brenner BG (2012) The impact of HIV genetic polymorphisms and subtype differences on the occurrence of resistance to antiretroviral drugs. Mol Biol Int 2012:256982

46. Wood E, Hogg RS, Yip B, Dong WW, Wynhoven B, Mo T, Brumme CJ, Montaner JS, Harrigan PR (2005) Rates of antiretroviral resistance among HIV-infected patients with and without a history of injection drug use. AIDS 19:1189-1195

47. Maia Teixeira SL, Bastos Fl, Hacker MA, Guimaraes ML, Morgado MG (2006) Trends in drug resistance mutations in antiretroviral-naive intravenous drug users of Rio de Janeiro. J Med Virol 78:764-769

48. Bakhouch K, Oulad-Lahcen A, Bensghir R, Blaghen M, Elfilali KM, Ezzikouri S, Abidi O, Hassar M, Wakrim L (2009) The prevalence of resistanceassociated mutations to protease and reverse transcriptase inhibitors in treatment-naive (HIV1)-infected individuals in Casablanca, Morocco. J Infect Dev Ctries 3:380-391

49. Pires IL, Soares MA, Speranza FA, Ishii SK, Vieira MC, Gouvea MI, Guimaraes MA, de Oliveira FE, Magnanini MM, Brindeiro RM, Tanuri A (2004) Prevalence of human immunodeficiency virus drug resistance mutations and subtypes in drug-naive, infected individuals in the army health service of Rio de Janeiro, Brazil. J Clin Microbiol 42:426-430

50. Paolucci S, Baldanti F, Zavattoni M, Comolli G, Labo N, Menzo S, Clementi M, Gerna G (2003) Comparison of levels of HIV-1 resistance to protease inhibitors by recombinant versus conventional virus phenotypic assay and two genotypic interpretation procedures in treatment-naive and HAARTexperienced HIV-infected patients. J Antimicrob Chemother 51:135-139

51. Zimmer JM, Roman F, Lambert C, Jonckheer A, Vazquez A, Plesseria JM, Servais JY, Covens K, Weber J, Van Laethem K et al (2008) Impact on replicative fitness of the G48E substitution in the protease of HIV-1: an in vitro and in silico evaluation. J Acquir Immune Defic Syndr 48:255-262 
52. Theys K, Deforche K, Vercauteren J, Libin P, van de Vijver DA, Albert J, Asjo B, Balotta C, Bruckova M, Camacho RJ et al (2012) Treatment-associated polymorphisms in protease are significantly associated with higher viral load and lower CD4 count in newly diagnosed drug-naive HIV-1 infected patients. Retrovirology 9:81

53. Tossonian HK, Raffa JD, Grebely J, Viljoen M, Mead A, Khara M, McLean M Krishnamurthy A, DeVlaming S, Conway B (2009) Primary drug resistance in antiretroviral-naive injection drug users. Int J Infect Dis 13:577-583

54. Valente MJ, Carvalho F, Bastos M, de Pinho PG, Carvalho M (2012) Contribution of oxidative metabolism to cocaine-induced liver and kidney damage. Curr Med Chem 19:5601-5606
55. Were T, Wesongah JO, Munde E, Ouma C, Kahiga TM, Ongecha-Owuor F, Kiarie JN, Ahmed AA, Makokha EP, Budambula V (2014) Clinical chemistry profiles in injection heroin users from Coastal Region, Kenya. BMC Clin Pathol 14:32

56. Rabi SA, Laird GM, Durand CM, Laskey S, Shan L, Bailey JR, Chioma S, Moore RD, Siliciano RF (2013) Multi-step inhibition explains HIV-1 protease inhibitor pharmacodynamics and resistance. J Clin Invest 123:3848-3860
Submit your next manuscript to BioMed Central and take full advantage of:

- Convenient online submission

- Thorough peer review

- No space constraints or color figure charges

- Immediate publication on acceptance

- Inclusion in PubMed, CAS, Scopus and Google Scholar

- Research which is freely available for redistribution

Submit your manuscript at www.biomedcentral.com/submit 